\title{
La naturaleza como sujeto y alternativa del desarrollo
}

Claudia Kuzma Zabaleta

Trabajadora Social

Montevideo, Uruguay

Resumen

La relación entre la naturaleza y el desarrollo en América Latina tiene diferentes avistas. Por esta razón, el tema debe ser abordado por la sociedad con una visión crítica del "desarrollo sustentable" y de la defensa del medio ambiente.

Palabras clave: desarrollo sustentable, medio ambiente y desarrollo, acuerdos internacionales, conceptos de naturaleza

\begin{abstract}
The relationship between nature and sustainable development in Latin America has different edges. That is why this topic must be analyzed by society from a critical point of view with regard to sustainable development and environment protection.
\end{abstract}

Keywords: Sustainable development, environment and development, international agreements, concepts of nature

\section{A modo de introducción}

D esde hace algunas décadas, ha ido ganando creciente legitimación en el ámbito académico (programas curriculares en formación de grado y posgrado en universidades públicas y privadas); en el discurso político (no existen campañas políticas, ni gobiernos o incluso tratados de integración comercial, ni organismos regionales e internacionales que no lo mencionen con entusiasmo y lo propongan para nuestras agendas nacionales y regionales) y en la opinión pública generada por los medios masivos de comunicación, un nuevo concepto: el "desarrollo sustentable". Junto a esta categoría aparentemente prometedora se ha vinculado otra noción también bastante difundida en todo nivel: el "medio ambiente".

Sin embargo, la relación entre estas dimensiones no parece generar aún en América Latina sociedades justas, igualitarias, capaces de satisfacer las necesidades de los sujetos, democráticas, respetuosas de las diferencias 
identitarias (étnicas, de género, generacionales, locales, etc.), sino que expresa múltiples contradicciones, deficiencias $\mathrm{y}$, sobre todo, destructivas consecuencias en todos los ámbitos. ¿Ello se debe a la insuficiente conciencia por parte de la sociedad respecto de lo que estas nociones pretenden denunciar? ¿O habría que atribuir el problema a la falta de voluntad política por parte de nuestros gobernantes para elaborar y ejecutar políticas nacionales donde se incorpore la perspectiva ambiental? ¿Es acaso que los organismos internacionales (Naciones Unidas, BID, $\mathrm{BM})$ y regionales (CEPAL) no han sido "escuchados" por nuestros gobiernos en sus recomendaciones y orientaciones en lo relativo a estos temas? O que, por el contrario, aunque dichos organismos son atendidos en sus lineamientos, el "inevitable" proceso de globalización reflejado en la necesidad de captar afanosamente inversiones extranjeras, colocar nuestros productos y servicios en los principales mercados mundiales, modernizar y transformar nuestros aparatos estatales minimizando gastos sociales e incorporarnos como "bloque regional" al proceso para mejorar nuestras oportunidades, nos limitan y condicionan en las posibilidades reales de llevar a cabo lo que tales organismos recomiendan. $\mathrm{O}$ en una visión más fatalista, nuestro mismo "subdesarrollo" nos condena a vivir el deterioro ambiental como una consecuencia natural y directa de esa condición histórica definida en relación al mundo "desarrollado" e "industrializado".

La búsqueda para encontrar respuestas a tales interrogantes y desafíos nos lleva a debatir críticamente a la luz de los aportes teóricos de autores latinoamericanos como E. Gudynas, Enrique Leff y Leonardo Boff entre otros, la compleja relación entre ambas dimensiones en América Latina. En este sentido, desde la presente investigación se plantea que tales contradicciones y limitaciones aún no superadas, responden al tipo de relación entre desarrollo y ambiente que produjo el proyecto civilizatorio de la modernización.

Un proyecto impuesto desde la conquista que significó la expansión del sistema capitalista bajo la lógica acumulativa y el absolutismo del mercado y que, desde hace algunas décadas, se expresa bajo nuevas formas y tendencias (denominadas como "globalización" o "mundialización"), donde podemos ubicar la aparición y legitimación de ciertos discursos "oficiales" sobre "desarrollo sostenible" y "medio ambiente". En tales discursos y conceptos si bien se incorpora la temática ambiental, lo hacen bajo el mismo paradigma de desarrollo basado en la racionalidad instrumental, en una visión utilitarista y mercantilista de la naturaleza. No existe en estas propuestas una visión alternativa de desarrollo donde la relación naturaleza-desarrollo adquiera centralidad transformando así el propio sistema y generando un nuevo orden social.

La investigación se inicia con las propuestas para la región desde los años 50 por parte de la CEPAL y un breve recorrido por las principales orientaciones y recomendaciones desde instancias y organismos de nivel internacional (Naciones Unidas: Estocolmo 1972, Río de Janeiro 1992; BID: Informes de 1997-99; BM: reformas estructurales) considerados como antecedentes del tema.

Pero el abordaje de la relación entre "desarrollo" y "ambiente" supone la 
deconstrucción del paradigma predominante en América Latina sobre desarrollo y de sus fundamentos filosóficos. Dentro de esta reflexión en torno al paradigma de desarrollo y sus consecuencias respecto a la naturaleza y el ambiente, se presentarán dos casos particulares a modo de ejemplo: a) Costa Rica en el marco del Tratado de Libre Comercio con Estados Unidos y los contenidos subyacentes en torno al "ambiente"; y b) el conflicto entre Argentina y Uruguay en el contexto del MERCOSUR, a partir de la instalación de las plantas procesadoras de celulosa en la zona fronteriza entre ambos países.

A partir de esta discusión, se presentará una serie de fundamentos filosóficos y éticos (como la "racionalidad ambiental") en forma propositiva para la construcción de un modelo alternativo de desarrollo en la región, donde se incorporen cada vez más las diferentes "identidades culturales".

Finalmente, desde el punto de vista metodológico, el trabajo consistirá en una investigación de tipo teórico a partir de la lectura crítica de los autores referidos y de los principales documentos regionales e internacionales sobre el tema. Desde estos aportes teóricos y de algunas investigaciones académicas realizadas por la Universidad Nacional (en el caso de Costa Rica), foros y espacios de discusión; así como por la Universidad de la República de Uruguay - Facultad de Ciencias (en el caso del Uruguay) y la información brindada en medios de prensa por distintos actores sociales involucrados directamente en el tema, se realizará el análisis y discusión de los mencionados casos.

\section{Antecedentes del tema}

“...Los sueños del mercado mundial son las pesadillas de los países que a sus caprichos se someten... seguimos aplaudiendo el secuestro de los bienes naturales que Dios o el Diablo nos ha dado, y así trabajamos por nuestra propia perdición y contribuimos al exterminio de la poca naturaleza que queda en este mundo... " (Eduardo Galeano).

En esta parte de la investigación, se presentará una reseña sobre los principales antecedentes -siguiendo un orden cronológico- del abordaje teórico del tema y sus repercusiones en América Latina.

Cabe mencionar brevemente que desde la independencia en el siglo XIX, las estrategias de desarrollo propuestas para la región se inspiraron en el modelo europeo y tuvieron como centro el crecimiento material. Se invocaban las riquezas naturales de cada país, los espacios vacíos que ocupar y la calidad de la población. Para ello, se diseñaban estrategias para extraer minerales, descubrir petróleo, ampliar la explotación agropecuaria y promover el desarrollo industrial. El acento estaba puesto en el crecimiento económico como generador del "progreso" social y político 1 .

Durante el siglo XX, la influencia de la Teoría de la Dependencia, promovida desde la CEPAL, representó -y aún representa- una visión latinoamericana sobre el desarrollo. Desde el estructuralismo y la dependencia como sustentos teóricos, el argentino R. Prebisch primeramente y posteriormente A. Gunder Frank y F. Cardoso criticaron

1 Gudynas, Eduardo (2002). "Concepciones de la Naturaleza y Desarrollo de América Latina”. En: Ecología, economía vética del desarrollo sostenible en América Latina. San José: EUNED, p. 19-57. 
las formas en que operaba el mercado internacional. Sin embargo, como señala E. Gudynas, aunque esta teoría constituye un importante aporte al denunciar la "desigualdad de las relaciones de intercambio" entre "centro" y "periferia", no dejaba de aspirar a la industrialización, al progreso económico y a la generación de excedente. La búsqueda por independizar a nuestros países se centraba en alcanzar una "sustitución de importaciones", pero no existía una visión alternativa de cómo articular el desarrollo con el ambiente. Se creía que los problemas ambientales podían ser solucionados por medios técnicos y predominaba un gran optimismo respecto a las reservas de recursos. Tanto los "dependentistas" bajo el paradigma estructuralista- como las propuestas desde el marxismo, sostenían la fe en el progreso técnico y en el manejo del ambiente como algo ajeno.

Otro antecedente en materia de propuestas para el desarrollo de la región, pero desde la teoría de modernización de Rostow, lo constituye la Alianza para el Progreso y el Desarrollo en la década de los 60. Con ella, se instituyen los Consejos Nacionales de Desarrollo en todos los países y se promueve la planificación económica, apostando al crecimiento industrial basado en tecnología de avanzada. A partir de esta propuesta se logró la tecnificación agraria y se constataron algunas mejoras en salud y educación. Sin embargo, no se llegó a satisfacer las necesidades de la población y se perjudicaron gravemente los ecosistemas: erosión del suelo, destrucción de bosques, avance de la frontera agropecuaria junto a procesos de desertificación, etc. Existió crecimiento pero sin desarrollo y se generó una degradación tanto humana como natural.
En 1972, el Instituto de Tecnología de Massachusetts (MIT) por encargo del Club de Roma presenta el documento "Los límites del crecimiento", donde la temática de la naturaleza que siempre había permanecido al margen del problema del desarrollo, adquiere un papel central en la discusión. En dicho estudio, se plantea que la naturaleza es limitada tanto en sus recursos como en la capacidad de amortiguar impactos ambientales. A su vez, se deja de invocar un crecimiento económico continuado ya que los recursos son considerados "finitos". No obstante, en América Latina este informe produjo una reacción contraria, que llevó a considerar los problemas ambientales como exclusivos de los países industrializados y ajenos a nuestra realidad. Las discusiones continuaron ese mismo año en la primera conferencia de las Naciones Unidas sobre ambiente y desarrollo en Estocolmo. A partir de esta instancia, la temática ambiental adquirió gran relevancia y se hizo explícita su relación con el desarrollo. Se estableció la responsabilidad de los países industrializados en la contaminación y en las consecuencias del crecimiento de la población. Los países latinoamericanos sostuvieron que cada Estado era soberano para manejar sus recursos naturales, pues "las normas ambientales de los países desarrollados no podían ser aplicables en los países en vías de desarrollo". Los dependentistas criticaban el enfoque ecológico e interpretaron el problema del ambiente como un síntoma más del subdesarrollo ("la pobreza es el primer problema ambiental en América Latina"). Se sospechaba, además, que los discursos ecológicos por parte de los países industrializados ocultaban otros aspectos relacionados con el comercio internacional y la intervención 
política. La respuesta más organizada contra el Instituto de Tecnología de Massachussets surge con la Fundación Bariloche (Argentina), donde se reconoce la posibilidad de una crisis ambiental pero se considera que ella es producto de un "sistema de valores destructivos". Por ende, la solución no consistiría en "medidas correctivas", sino en "la creación de una sociedad intrínsecamente compatible con su medio ambiente". Sin embargo, no aceptan los límites al desarrollo invocando el mito de los recursos infinitos, atribuyendo a la tecnología la capacidad para controlar todos los problemas ambientales y desestimando la posibilidad de conocer cuáles recursos serían no renovables. En esta instancia, todos los aspectos se reducen a un problema político, donde se cuestiona el orden económico internacional y se apuesta a un futuro esperanzador para la región. En definitiva, la respuesta de la Fundación Bariloche constituye una expresión más de las posturas desarrollistas tradicionales.

Entre la primera Conferencia de Estocolmo en 1972 y la siguiente en Río de Janeiro en 1992, se produjo un intenso debate donde algunos países como Brasil defendieron la intensificación de los recursos naturales. También abundaron los estudios sobre los impactos ambientales, la extinción de especies y la acción de los contaminantes. Surgen así corrientes de análisis desde una sensibilidad ambiental (como la economía ecológica o la ética ambiental); y se toma conciencia de los problemas como la contaminación urbana o la destrucción de áreas naturales que ocurrían en América Latina (México, la selva Amazónica). Se producen algunos avances metodológicos con la elaboración de diagnósticos ambientales por parte de la Oficina Regional del PNUMA en 1976 y los estudios realizados a partir del Seminario de Medio Ambiente y Desarrollo de 1979 organizado por el PNUMA y la CEPAL.

En 1983, las Naciones Unidas crean la Comisión Mundial de Medio Ambiente y el Desarrollo, para explorar las relaciones entre los temas de desarrollo y los ambientales. La comisión, que contó con comisiones técnicas y varios miembros latinoamericanos, realizó consultas públicas en distintas ciudades y regiones.

En 1987, dicha Comisión presenta el estudio "Nuestro Futuro Común" o "Informe Brundtland", pensado y escrito para políticos y tomadores de decisiones, a partir del cual se consolida el concepto del "desarrollo sostenible ${ }^{2}$, el cual se define aquí como “...

2 El término "sostenible" proviene del latín: "sustinere" que significa sustentar, mantener elevado. Desde una perspectiva ecológica es el mantenimiento de la base de los recursos naturales. El concepto nace primero en los países anglosajones ("sustainable development") y se difunde en el mundo gracias a estudios realizados en la década de los 60 y 70, donde se establecía que los problemas ambientales eran consecuencia directa de las estrategias de desarrollo. Con la presentación de la primera Estrategia Mundial para la Conservación realizada en 1981 por la IUCN (Unión Internacional para la Conservación de la Naturaleza) con el apoyo del Fondo Mundial para la Vida Silvestre y el PNUMA, se elabora una definición que deja en claro que el desarrollo es una forma de modificación de la naturaleza y por tanto deben ponerse en la balanza los objetivos de satisfacer las necesidades humanas en relación con sus impactos. A pesar de estos avances, la postura queda incorporada a la Estrategia Internacional del Desarrollo de la ONU, la cual buscaba cambios en el orden económico, pero no ofrece una visión alternativa de desarrollo. El término comienza a ser utilizado también por el Banco Mundial en 1981, señalando que "un desarrollo sostenido debe permitir un crecimiento continuo". En definitiva, se trata de un concepto plural que ha ido recibiendo distintas definiciones a lo largo del tiempo; pero lo más importante es su articulación dentro de las estrategias de desarrollo y la gestión ambiental. (Gudinas, 2002: 59-82) 
el desarrollo que satisface las necesidades de la generación presente sin comprometer la capacidad de las generaciones futuras para satisfacer sus propias necesidades "... .

Si bien, como plantea H. Sejenovich, esta instancia de acuerdo global constituye una oportunidad para debatir la perspectiva latinoamericana del "desarrollo sustentable" y su viabilidad a partir de una profundización de la democracia, adolece de importantes omisiones. Por ejemplo, aunque se preocupa por las "generaciones futuras", no menciona el problema de la desigualdad creciente entre ricos y pobres, ni plantea una distribución equitativa de los recursos. Por otra parte, si bien el informe parece reconciliar la oposición entre "ecología" y crecimiento, colocando la dimensión ambiental como "un requisito más del progreso económico y del desarrollo", en realidad no significó un cambio del paradigma tradicional de desarrollo -definido como crecimiento económico y una visión utilitarista de la naturaleza-, sino que lo termina reforzando. En ese sentido, el informe es un ejemplo de cómo estas corrientes de pensamiento se apropiaron de conceptos ecológicos transformaron en función de sus objetivos. (Gudynas, E; 2002).

Posteriormente, como seguimiento a "Nuestro Futuro Común", el Programa de Naciones Unidas para el Desarrollo (PNUD), el BID, la CEPAL y el Programa de Naciones Unidas para el Medio Ambiente (PNUMA) presentan "Nuestra Propia Agenda", en el contexto de la segunda Conferencia sobre Medio Ambiente y Desarrollo, realizada en Río de Janeiro en 1992. Dicho estudio, analiza detenidamente los principales problemas que afectan nuestra región y destaca la pobreza (aunque como causa del deterioro ambiental) y la desigualdad, que evidencian la crisis del proyecto actual de civilización. Este documento, junto a una serie de acuerdos ${ }^{3}$ realizados en dicha conferencia, significaron un avance en identificar los vínculos entre los aspectos ambientales con los del desarrollo, particularmente respecto a Sudamérica. No obstante, se mantienen algunos presupuestos sobre desarrollo:se concibe la naturaleza como recursos que deben ser aprovechados en beneficio de la economía, la idea del crecimiento continuo y el desarrollo material.

Dentro de esta concepción de naturaleza y ambiente subordinados al desarrollo económico, es preciso señalar brevemente el papel que ha jugado el BID desde sus informes técnicos de 1997, 1998-99. Basado en una visión eurocentrista (a semejanza de los intelectuales criollos o extranjeros que buscaban "civilizar la cultura bárbara"), dicho organismo ha buscado imponer en nuestra región el modelo de las sociedades industrializadas del norte, como ejemplos de "progreso" e "igualdad". Según el BID, cuanto más rico sea un país en

3 Durante esta, los gobiernos acuerdan cinco documentos: a) La Declaración de Río sobre Medio Ambiente y Desarrollo; b) la Agenda 21, un programa de acciones sobre las relaciones entre desarrollo y ambiente; c) una declaración sobre los bosques, con principios para su uso y conservación; d) la Convención Marco de las Naciones Unidas sobre el Cambio Climático y e) el Convenio sobre la Diversidad Biológica, sobre protección y uso de los ecosistemas, su fauna y flora. Cabe mencionar que, paralelamente, las organizaciones no gubernamentales redactaron y difundieron una serie de convenios alternativos sobre esos y otros temas analizados durante la cumbre. 
recursos naturales, más lento será su desarrollo ${ }^{4}$; pues la alta desigualdad del ingreso en América Latina se debe en especial a la riqueza en recursos naturales: los países tropicales tienden así a ser más pobres y desiguales. Entre las razones que destaca para ello, se encuentra la característica de los cultivos tropicales como el algodón, el azúcar y el tabaco, los cuales se producen en plantaciones de gran escala, que refuerzan la concentración; mientras que los cultivos templados la revertirían. Este tipo de afirmaciones olvidan que no existe una condición ecológica que obligue a desarrollar determinado cultivo a los pequeños o grandes propietarios. Es decir, las condiciones ambientales no imponen contextos económicos, sino que éstos determinan cuáles son las superficies más ventajosas para un propietario. El BID insiste en que la concentración de la tierra, las relaciones verticales y jerárquicas y las divisiones de clases, tienen una condicionante ambiental. Este enfoque es calificado por Gudynas como un "fatalismo ambiental" que desconoce los determinantes históricos, económicos y políticos tanto en el patrón de propiedad como en las estructuras sociales y políticas actuales. Este mecanicismo fatal impide todo análisis crítico para buscar alternativas de desarrollo.

4 El BID correlaciona los niveles de desigualdad (medidos por el coeficiente de Gini) con la disponibilidad de recursos. Encuentra que los países cercanos al ecuador poseen sistemáticamente mayores inequidades en el ingreso; es decir los países tropicales cuyas economías son intensivas en tierra y recursos minerales, tienden a ser más desiguales. Las tierras tropicales y sus cultivos ofrecerían la posibilidad de grandes economías de escala bajo condiciones climáticas más adversas y con menores innovaciones tecnológicas que en zonas templadas. Los recursos naturales son "sumideros de capital" en tanto succionan capitales intensamente, haciéndolo más escaso y generando poco empleo. (Gudynas, 2002)
A su vez, el Banco Mundial con las llamadas "reformas de la segunda generación" en la década de los 90 y sus nuevas estrategias de desarrollo, ignora las implicaciones ambientales. El objetivo central de tales estrategias es asegurar el crecimiento económico como motor del desarrollo, reforzando el mercado pero dejando algunas tareas al Estado. Se pone énfasis en la inversión en "capital humano" que busca la educación y adquisición de habilidades y competencias para aumentar la productividad de los obreros y las economías; promover reformas de flexibilización laboral y ceder a los privados la inversión en infraestructura (represas, carreteras, etc.). Este economicismo se percibe hasta en el tema de la violencia urbana, la cual se debe combatir no sólo por su impacto en las personas sino por los costos económicos.

En definitiva, aunque las mencionadas instancias y organismos internacionales han abordado el problema de la relación entre desarrollo y ambiente, llegando a firmar varios acuerdos por parte de los gobiernos, los cambios no parecen producirse. Pero además, la concepción sobre "desarrollo sustentable" ha recibido, a lo largo de estos años, variados contenidos como respuesta a diferentes corrientes de pensamiento donde parece prevalecer la economicista que sustenta el sistema actual. Por eso, el siguiente apartado se concentra en discutir críticamente tales corrientes que no han permitido abordar la compleja relación entre desarrollo y ambiente en América Latina. 


\section{"Desarrollo sustentable" y "medio ambiente" en América Latina: conceptos y paradigmas}

\begin{abstract}
"Sin pata de palo, ni parche en el ojo, andan los biopiratas por la selva amazónica y otras tierras... cuatrocientos pueblos indigenas de la región amazónica han denunciado recientemente a la empresa internacional Plant Medicine Corporation, que se ha apoderado de una planta sagrada: la ayahuasca... La empresa elabora con ella remedios para enfermedades psiquiátricas y cardiovasculares... la ayahuasca es ahora propiedad privada...” (E. Galeano).
\end{abstract}

Los antecedentes presentados en el apartado anterior expresan que la relación desarrollo y ambiente en América Latina está signada por reduccionismos economicistas por parte de los expertos de organismos regionales e internacionales, intereses lucrativos de empresarios y hasta de nuestros gobiernos, así como un reduccionismo temático en el campo de las ciencias biológicas ${ }^{5}$.

Las estrategias de desarrollo impulsadas en América Latina desde los organismos internacionales y regionales, así como las políticas de desarrollo aplicadas por los gobiernos nacionales, parecen reflejar más allá de nuevos conceptos ("desarrollo sostenible"), que el paradigma economicista y la mercantilización siguen predominando

$5 \quad \mathrm{Al}$ respecto, cabe mencionar brevemente que en gran parte de la ecología los objetivos de estudio en las universidades han excluido las intervenciones humanas en los temas ambientales. Se ha insistido en que la ecología es una "ciencia" que estudia las relaciones de los seres vivos entre sí y su ambiente, excluyendo a los seres humanos y cualquier componente social. Las influencias de las acciones humanas sobre el ambiente fueron entendidas como interacciones que vienen desde fuera del sistema. Sin embargo, "el ambiente" consiste en una "totalidad organizada" constituida por diversidad de procesos, que se desarrollan tanto en la sociedad como en la naturaleza. (Fernández, 2006) por encima de ideologías de izquierda o de derecha, de discursos progresistas que buscan la justicia social o de discursos ecologistas y ambientalistas. Hoy más que nunca debemos cuestionar y analizar las nociones que se manejan sobre desarrollo, pero sobre todo las concepciones sobre ambiente y naturaleza que subyacen en ella. Ambas nociones se encuentran interrelacionadas -como menciona Gudynas, existe una relación "dialéctica entre ellasde manera tal que analizar conceptos de naturaleza nos conduce a considerar paradigmas de desarrollo y viceversa.

Comencemos por profundizar las distintas concepciones ${ }^{6}$ sobre "naturaleza" y sus fundamentos filosóficos y terminemos por presentar algunos "mitos sobre el desarrollo" -siguiendo el análisis de Sejenovich-que han influido notoriamente en América Latina.

La palabra "naturaleza" proviene del latín (natus, o sea nacer) y recibe dos acepciones: como propiedades de un objeto o ser y como "ambientes" que no son artificiales, con especies de flora y fauna. Bajo este último significado, la naturaleza ha sido considerada como el origen de la riqueza de un país, pero también como un medio "salvaje" y "peligroso".

Las ideas predominantes en América Latina sobre naturaleza han estado influidas por las visiones europeas: junto a los conquistadores llegan las ideas sobre naturaleza propias de su cultura. Luego, durante la formación de las repúblicas, los políticos e intelectuales criollos de la región se forman con tales ideas. Distanciada del pensamiento medieval -que veía la naturaleza como un

6 Gudinas (2002. 19-57).. 
ser vivo y a las personas como un componente más-; la idea de naturaleza del Renacimiento europeo (F. Bacon, R. Descartes, etc.) es marcadamente "antropocéntrica", donde se distingue entre elementos vivos y no vivos, los cuales son objeto de manipulación. Dicha concepción antropológica de la naturaleza - según algunos autores- tiene sus raíces en la herencia occidental: la tradición judeo-cristiana y la cultura helénica. También es considerada una máquina y por tanto analizada en "sus piezas". Era aquella que ofrecía recursos, pero a la vez se concebía como "incontrolable" y, por tanto, el ser humano debía conocerla para dominarla.

Así, desde el Renacimiento la diferencia entre el ser humano y su entorno se acentúa y el ser humano adquiere un rol por fuera de la naturaleza que pasa a ser apropiada y manipulada como condición y necesidad para alcanzar el "progreso" perpetuo. Los primeros economistas como Adam Smith y John Stuart Mill promueven las ventajas del progreso material y el dominio de la naturaleza. Pero también Compte, Hegel y Marx -a pesar de las diferencias ideológicas- mantuvieron el "progreso material" como idea predominante.

De esta forma, se expande "la misión" en América Latina de "civilizar" la naturaleza, para que ofrezca sus frutos y riquezas. Se busca ocupar espacios "salvajes", tanto en la época de la conquista como al inicio de las repúblicas independientes. El avance de la colonización implica "suprimir a los indios" y poblar "el desierto", imponiéndose así una visión utilitarista donde la naturaleza se constituye en "canasta de recursos", desvinculados unos de otros. Lo importante es la eficiencia y productividad (el valor mercantil) en la extracción de recursos y aprovecharlos desde las estrategias de desarrollo.

Entre los siglos XVIII y XIX, se difunde la idea de que el atraso de América Latina se debe a las trabas culturales y políticas, pero no a límites ambientales. Los indios y criollos eran considerados un obstáculo para el "uso" de la naturaleza, por ello se atraen inmigrantes europeos para "civilizar" a la población. En definitiva, conjuntamente con el trasplante de pueblos (Ribeiro, 1972), se trasplanta el concepto de naturaleza, reproduciendo, de esta forma, paisajes europeos en nuestros países.

En este contexto, aparecen ideas "conservacionistas" en América Latina procedentes de Europa que buscan más que proteger la naturaleza, conservar los recursos que sostienen la economía. Esta tendencia se difunde en varias áreas de la producción agrícola y ganadera. La naturaleza es "fragmentada": hay una para el geólogo, otra para el productor agrícola, otra para el planificador de urbanizaciones, etc. No existe una visión holística de la naturaleza.

Paralelamente, surge la ecología como ciencia, pero como se mencionaba anteriormente también concibe la naturaleza como una máquina, con mecanismos y funcionamiento bajo "leyes" que el hombre no debe violar. Aunque desde la ecología, la naturaleza poseía unidad y dinámica interna. En 1935, aparece el concepto de "ecosistema". Esta noción llegó a reemplazar la de naturaleza, con un carácter manipulativo más que relacional. El ecólogo es quien debe brindar información para intervenir en la naturaleza y conseguir 
mejores éxitos. La ecología clásica introduce la idea de una naturaleza frágil, con un orden propio que se constituye en un marco conceptual para las propuestas de articulación entre conservación y desarro1lo. Dicha perspectiva influyó fuertemente en el pensamiento cepalino de 1992.

A partir de la década de los 80 , surge una perspectiva originada en la economía y que se extiende entre diferentes corrientes: desde liberales y neoliberales hasta en el keynessianismo. Todos conciben la naturaleza como una forma de "capital". Esta perspectiva llega a América Latina y abarca a varios pensadores y a la CEPAL que en sus propuestas sobre "transformación productiva con equidad", entiende el "desarrollo sostenible" como un equilibrio entre formas de capital y entre ellos menciona el "capital natural". Esta postura propaga la racionalidad económica, el antropocentrismo, la manipulación y utilización de la naturaleza, donde su valor se restringe al uso e intercambio asignados por el ser humano. Todo se mercantiliza: la protección del ambiente es una forma de "inversión", los ciclos ecológicos son "servicios" que ingresan al mercado, etc. Se imponen los criterios de eficiencia y beneficio económico y se desestiman los valores ecológicos, culturales o estéticos.

Como consecuencia de estas posturas, la naturaleza aparece fragmentada, pierde cohesión y unidad. Ella es desagregada en distintos componentes que son reconocidos en función de su valor económico y cada uno de esos componentes debe tener dueños; aparecen los derechos de propiedad sobre los ecosistemas (ríos y cursos de agua, patentes sobre microorganismos y cultivos). El ser vivo pierde interés en relación con alguno de sus atributos genéticos comercializados, regulados por patentes y derechos de propiedad.

Las propuestas de desarrollo mencionadas como antecedentes en este artículo consideran el crecimiento económico como necesario para América Latina, y esto se observa tanto en las posturas de origen neoliberal como en las de izquierda (marxista o no marxista). Las diferencias entre paradigmas de desarrollo se encuentran en las finalidades y medios (rol del Estado, del mercado, etc.).

En todas existe una idolatría hacia el progreso y la visión mecanicista de la sociedad que siempre debe "avanzar". El progreso material, la acumulación de capital y el aumento de bienes son "indicadores" de tal avance. Predomina, entonces, la "racionalidad instrumental", donde los medios adquieren el lugar de los fines o metas. Se minimizan las restricciones ambientales al desarrollo; la naturaleza casi no aparece o si lo hace es en forma subsidiaria. La perspectiva frente al ambiente es marcadamente antropocéntrica: la naturaleza al servicio del hombre, por eso no posee valores propios ni derechos, se convierte en canasta de recursos, en una máquina, un sistema o forma de capital.

Actualmente, con el concepto de "desarrollo sostenible", la naturaleza que se encontraba fuera del desarrollo ahora es explícitamente incorporada y deja atrás la oposición entre desarrollo y ambiente. Pero esta nueva vinculación sólo mantiene y refuerza la ideología del progreso. El "ambiente" (como sinónimo de 
naturaleza) se convierte en una condición para el crecimiento económico.

La mercantilización del desarrollo y la naturaleza es el eje común en la mayoría de las propuestas predominantes en América Latina, donde la estrategia es pensada en función del mercado y el Estado se convierte en un simple medio. Mientras el objetivo sea el crecimiento económico, el mercado continuará siendo el protagonista. Todas las otras áreas, como salud y educación son analizadas y planificadas desde el mercado ("capital humano", "gasto social", "mercado laboral"). Pero el crecimiento económico no puede ser un fin en sí mismo, sino uno de los componentes en el desarrollo. Dicha ideología mercantilista está presente aún en las nuevas y más recientes visiones sobre la naturaleza. Es decir, en las últimas décadas han surgido conceptos que incorporan nuevos aspectos sobre la naturaleza (biodiversidad), revelan la preocupación por la extinción de la flora y la fauna y de los ecosistemas ("espacios silvestres"). No obstante, muchas de estas nuevas perspectivas han sido cooptadas por el mercado y el paradigma economicista del desarrollo. Es el caso de la "biodiversidad" 7 que, si bien genera una imagen de unidad y enfatiza la particularidad de la diversidad, cae en una visión fragmentada del entorno natural, por lo cual puede ser manejada fácilmente por la concepción economicista.

7 Este concepto comprende tres tipos de elementos: a) las distintas especies de fauna, flora y microorganismos, b) la variabilidad genética que posee cada una de las especies y c) los ecosistemas, incluyendo las especies y los elementos físicos. Surge en 1988, y llegó a suplantar el término naturaleza. Durante la Conferencia de Medio Ambiente y Desarrollo de 1992, se firmó un tratado internacional sobre "biodiversidad". (Gudynas, 2002)
Por su parte, la corriente de científicos y militantes conservacionistas que detenta una visión de la naturaleza como "espacios silvestres" en América Latina, si bien ha fomentado una preocupación por la conservación de determinadas especies y por superar la connotación negativa de "salvaje" (término que proviene del latín "salvaticus" que refiere al bosque), propone como estrategia mantener intocadas determinadas áreas. La naturaleza aparece así como un espacio idílico, donde la cooperación y simbiosis entre seres vivos es propuesta como ejemplo para la humanidad. Surgen muchas organizaciones de conservación regionales e internacionales en Latinoamérica (WWF, Conservation International, etc.) que convierten en "problema" la presencia de indígenas y campesinos en los parques nacionales y "áreas protegidas", pues no compatibilizan con su idea de "naturaleza" sin personas. Sin embargo, las áreas llamadas "silvestres" han sido históricamente el hogar de numerosos grupos indígenas en América Latina. Los bosques tropicales en Mesoamérica y la región Andina constituyeron el hábitat de extensas poblaciones indígenas desde tiempos prehispánicos. En la actualidad, ellas llegan a los 45 millones de personas.

Finalmente, cabe reseñar brevemente algunos de los "mitos del desarrollo"8 que más han influido en América Latina, a saber:

- "La sociedad más desarrollada muestra la meta y el camino de las sociedades de menor grado de desarrollo". En su momento, Roma, España y Estados Unidos jugaron ese papel. Conjuntamente con este mito,

8 Sejenovich, s.d. 
existe el concepto de "cerrar la brecha" como estrategia de desarrollo de los diferentes países, suponiendo que existe un único camino. Este mito se encuentra en crisis -entre varias razones- porque la imitación del modelo de consumo de energía de los Estados Unidos acabaría con el planeta. Pero además, no se puede aplicar un mismo patrón en zonas tan diversas cultural y políticamente.

- "Existe una solidaridad entre crecimiento cuantitativo del producto bruto y la disposición de bienes por parte de la población, y entre esta disposición y el bienestar de esta”. Sin embargo, se ha constatado que a pesar de alcanzar el crecimiento, no se ha logrado el bienestar, a causa de la alta concentración del ingreso. A su vez, los sectores que habían alcanzado cierto grado de satisfacción de sus necesidades básicas, no lograron mejorar su calidad de vida, debido al estrés de las ciudades, agresividad, pérdida de libertad, de participación, dificultades en el transporte, etc.

- "La estrategia del desarrollo debe basarse en la máxima utilización de las ventajas comparativas que brinda el país". Este mito ha generado una explotación masiva de los elementos naturales que tienen ventajas de nivel internacional, desaprovechando así un inmenso potencial que podría satisfacer las necesidades básicas de la población; exportación al mercado mundial de los elementos naturales utilizables para obtener divisas que compren bienes para el consumo; reacomodamiento de la economía a las condiciones exigidas por la máxima utilización del sector más ventajoso; y otras.

- “El tamaño cada vez mayor de las fábricas permitirá obtener economías de escala y reducir los precios". Este mito llevó al gigantismo ingenieril con efectos negativos en contaminación, en obras de infraestructura y en proyectos agrarios.

- “El proceso de urbanización es signo de progreso y su tendencia seguirá manteniéndose en el futuro”. Queda demostrado el fracaso de este mito y de la reforma agraria, ante la profunda crisis ambiental que viven nuestras ciudades (San Pablo, México, Santiago).

- "Los recursos son infinitos". Sobre este aspecto ya se ha hablado anteriormente.

- "La tecnología es sólo un instrumento”. Este mito desconoce que la tecnología lleva implícita la sociedad que la ha generado. Ella no es neutra. Por tanto, es necesario generar una estructura científica que nos permita una adecuada relación con la naturaleza.

- "La realidad debe estudiarse y planificarse de acuerdo con los sectores que la integran”. La planificación del desarrollo evidencia el sectorialismo que impide ver las interacciones y alcanzar una visión más global. 
En definitiva, el desarrollo, el ambiente y la naturaleza en cuanto categorías, son creaciones sociales que responden a distintos momentos históricos. Ante la evidente crisis ambiental, social y económica que vive hoy no sólo América Latina sino el planeta todo, es necesario un mayor debate y discusión sobre estos temas hacia la formulación de alternativas de desarrollo donde el mercado y la racionalidad instrumental a su servicio pierdan protagonismo y se integre la dimensión ambiental en forma compleja, como más adelante se tratará. Como un aporte a esta discusión se expondrán brevemente dos casos que a pesar de las diferencias que puedan encontrarse en los contextos sociopolíticos, ejemplifican la permanencia del paradigma economicista en sus estrategias y políticas nacionales y regionales.

\section{Costa Rica: desarrollo y medio ambiente en el Tratado de Libre Comercio con Estados Unidos}

Costa Rica se encuentra inmersa, desde hace años, en el Tratado de Libre Comercio entre Estados Unidos y Centroamérica. Dicho tratado ha generado debates y cuestionamientos tanto desde el ámbito académico (donde las universidades públicas han desempeñado un importante papel), como desde distintas fuerzas sociales y políticas (sindicatos, movimientos populares, ambientalistas, estudiantiles, campesinos, etc.) de Costa Rica.

Y es que tanto el mencionado proceso de aprobación en Centroamérica, pasando por su estructura y alcance jurídicos, como los ejes centrales de su contenido, revelan una clara desigualdad entre las partes, donde la subregión particulariza la situación de vulnerabilidad que vive la región latinoamericana, sobre todo por la deficiente calidad de sus democracias, frente a la hegemonía económico-militar de los Estados Unidos. Una hegemonía del modelo neoliberal que se viene manifestando desde las "reformas de ajustes estructurales" impuestas desde el Banco Mundial junto al Fondo Monetario Internacional y el proyecto del Área de Libre Comercio para las Américas, truncado recientemente por las naciones sudamericanas.

Cabe señalar, en primer término, que la subregión centroamericana no ha sabido o no ha podido actuar como bloque frente a los Estados Unidos, dejando ver así las limitaciones del SICA y del modelo de desarrollo que subyace en dicho esquema de integración. No es cometido de este trabajo analizar el proceso de integración centroamericano, pero alcanza con mencionar que no ha existido una postura o estrategia como bloque frente a los intereses políticocomerciales de los Estados Unidos desde el TLC en Centroamérica. Por el contrario, cada país ha preferido buscar su ventaja particular repercutiendo así en las posibilidades y oportunidades del conjunto hacia un modelo de desarrollo alternativo. Pero, además, al interior de cada país no existió una convocatoria a la participación de todos los sectores afectados, ni canales o espacios para un verdadero debate nacional y público donde la ciudadanía pudiera informarse en profundidad y así pronunciarse en un tema tan importante. De esta forma, el TLC se impone desde Estados Unidos hacia las naciones centroamericanas y dentro de ellas se busca legitimar desde las cúpulas políticas (amparadas en un simulacro de la representatividad de la "democracia") 
hacia la sociedad, afectando, de esta manera a los sectores más vulnerables.

En segundo lugar, es preciso señalar que en el TLC subyace claramente un modelo de desarrollo neoliberal, donde la inserción en el mercado mundial se presenta como la panacea del desarrollo, de las "oportunidades" de la región para "superar la pobreza". En este sentido, aunque dicho tratado es presentado como el establecimiento de una "zona de libre comercio" en Centroamérica, constituye un proyecto de verdadera reforma económica, social, política y jurídica que definirá el futuro de toda la subregión y, en particular, de la sociedad costarricense $^{9}$. Se promueve la inserción en el mercado estadounidense en un contexto de profundas desigualdades entre las partes, en perjuicio de los países centroamericanos. Basta mencionar el alcance jurídico del TLC, el cual para los Estados Unidos consiste en un "acuerdo" de libre comercio que no supone superioridad de las disposiciones del TLC sobre sus leyes internas; mientras que para los países de Centroamérica, implica un "tratado" que adquiere superioridad sobre sus leyes nacionales. Porque en definitiva, el TLC no consiste en un tratado de "libre" comercio, ya que Estados Unidos -como señala el reconocido economista J. Stiglitz- utiliza medidas proteccionistas para bloquear las mercancías extranjeras. Como tampoco se restringe solamente al comercio de bienes y servicios estableciendo normas liberalizadoras para la importación y exportación, sino que impone reglas supranacionales en áreas claves para el desarrollo como

9 Mora Jiménez, Henry. (2004). "101 razones para oponerse al Tratado de Libre Comercio entre Centroamérica y Estados Unidos". Heredia: ESEUNA la propiedad intelectual, el ambiente, la inversión, la agricultura, los temas laborales, las disputas judiciales, políticas públicas, el papel del Estado, lo cual afectará el tejido social de la nación. Las leyes nacionales se volverán obsoletas, otras serán reformadas o adaptadas a las condiciones del "libre comercio". (Mora, 2004).

Por otra parte, los criterios para la reducción de aranceles buscan favorecer a determinados sectores (empresarios, importadores, exportadores, etc.) con mayor capacidad de presión y negociación, perjudicando de este modo a los pequeños productores agropecuarios. El TLC establece, pues, una serie de medidas para transformar la economía nacional siguiendo los criterios de la "competitividad", sin considerar las necesidades, potencialidades y propuestas de los sectores estigmatizados como "no competitivos" para el mercado.

En definitiva, el modelo de desarrollo impulsado por el TLC se reduce a la inversión de capitales transnacionales (sobre todo financiero-especulativo) estadounidenses en la región centroamericana con total libertad de acción.

En tercer lugar, dentro de este paradigma economicista de "desarrollo" que propone el TLC, en el cual las otras dimensiones se convierten en subsidiarias a la economía, bloqueando toda posibilidad y autonomía para elaborar estrategias nacionales de desarrollo, importa analizar el tema ambiental ${ }^{10}$. Así pues, en el TLC se

10 López. Manuel (2004). El problema ambiental: Ahora resulta que la enfermedad cura. En: Reflexiones en torno al Tratado de Libre Comercio. Razones para su rechazo. Carlos Aguilar Sánchez (ed.). San José: Colección Universitaria, p. 121-127. 
establecen normas sobre propiedad intelectual que tendrán un fuerte impacto sobre la naturaleza (patentes sobre especies de plantas y animales, microorganismos, etc.). Pero también sobre las costumbres y tradiciones de los campesinos y comunidades indígenas que serán afectados en su identidad debido a esta mercantilización de la naturaleza. Y es que existe un interés económico en la "biodiversidad" de la región mesoamericana (la cual representa el $7 \%$ del planeta), dado que representa un recurso estratégico para el "desarrollo tecnológico" en los campos de la biotecnología. Los bosques y las enormes reservas de agua en la región representan un stock de recursos importante para los Estados Unidos, que padece serios problemas ambientales. Además, Centroamérica constituye un corredor terrestre y marítimo para el comercio de bienes hacia el Norte. Este énfasis económico del TLC sobre lo ambiental, queda claramente explicitado cuando establece que “...las partes reconocen la importancia de promover el desarrollo sostenible junto con el fortalecimiento de las relaciones comerciales y de inversión”.

Dentro de esta mercantilización de la naturaleza que el TLC promueve, podemos identificar también su incidencia en los servicios públicos de Costa Rica relacionados con sus recursos naturales.

Es decir, por una parte se limita la capacidad de decisión y autonomía del Estado para regular la protección del ambiente en la prestación de servicios de seguros, telecomunicaciones, turismo, energía, educación, salud y suministro de agua, en función de los intereses comerciales. Y por otra, se establece entre las prioridades de cooperación ambiental, "el desarrollo y promoción de bienes y servicios ambientales beneficiosos" (anexo 17.1, art. 3, inc. h), sin explicitar qué se entiende por "bienes y servicios ambientales", aunque es claramente proclive a la privatización del suministro del agua y otros "servicios ambientales". A la vez prohíbe establecer restricciones o condiciones a favor del país, pero contrarias a los inversionistas, lo cual obliga a mantener leyes que deterioran el ambiente (Ley de Hidrocarburos, Ley de Generación Privada de Electricidad, etc.). Resulta difuso y ambiguo en algunas regulaciones que podrían ser perjudiciales para el ambiente: "expropiaciones indirectas", "actos regulatorios no discriminatorios", etc. El TLC permite a las partes "consultar dentro de la OMC sobre los acuerdos ambientales multilaterales" ya firmados por Costa Rica. A esta ambigüedad, se le suma que los Estados Unidos no se han adherido al Convenio de Kyoto o el de Biodiversidad, que constituyen instancias fundamentales respecto al medio ambiente en el nivel mundial. Pero además, en el marco de esta regulación ambiental confusa y ambigua, no se incluyen a los sectores vinculados directamente con los territorios que despiertan tanto interés y preocupación (comunidades campesinas, indígenas, pequeños productores, etc.), para la definición de estrategias de protección de la naturaleza.

Finalmente, aunque el TLC establece la creación de un "Consejo de Asuntos Ambientales", no existe, dentro de sus funciones, la de examinar los impactos de las actividades comerciales sobre el ambiente, ni modificarlas en caso de que representen una explotación de la naturaleza. Por otra parte, debilita la jurisdicción de 
los ministros de medio ambiente y prioriza a los de comercio. Ello viene a profundizar aún más los efectos del proceso de ajuste estructural del Estado costarricense, cuya capacidad de gestión en materia de sustentabilidad ambiental y social ha quedado debilitada: el Ministerio de Ambiente y Energía de Costa Rica carece de presupuesto y personal capacitado, desarrollando así una política acentuadamente descoordinada con el resto de los ministerios nacionales. Esto contribuye al tratamiento fragmentario del ambiente. Este tratamiento de la naturaleza en Costa Rica se profundiza a partir de las transformaciones económicas de la década de los $80 \mathrm{y}$ produce fuertes impactos socioambientales. Por ejemplo, el uso excesivo de agroquímicos, la amenaza de los acuíferos, el empobrecimiento de los campesinos y su migración a la ciudad, la pérdida de biodiversidad a causa de los monocultivos, la permanente amenaza ambiental en varias comunidades debido al excesivo y desequilibrado desarrollo turístico, etc.

\section{Conflicto en el MERCOSUR por el medio ambiente: Argentina versus Uruguay}

\begin{abstract}
"La celulosa se ha convertido en algo así como una causa patriótica, y defender la naturaleza no despierta entusiasmo... palabras como ecologista y ambientalista, se están convirtiendo en insultos... Más vale morir de contaminación que de hambre... los desocupados creen que no hay más remedio que elegir entre dos calamidades, y los vendedores de ilusiones desembarcan ofreciendo miles y miles de empleos...” (E. Galeano).
\end{abstract}

A lo largo del 2006, se generó entre países vecinos mercosurianos (Argentina y Uruguay) una serie de confrontaciones, manifestaciones públicas de cancilleres respectivos $\mathrm{y}$, sobre todo, movilizaciones populares (cortes de ruta por parte de "piqueteros" de Gualeguaychú, Entre Ríos -provincia argentina limítrofe con Uruguay-), hasta adquirir el carácter de conflicto internacional y requerir la intervención de la Corte Internacional de Justicia de La Haya. La causa del conflicto consiste en la instalación de dos plantas procesadoras de celulosa por parte de la empresa española ENCE y la finlandesa Botnia, en Fray Bentos, departamento de Río Negro a orillas del Río Uruguay, límite natural entre ambos países cuya jurisdicción comparten y el impacto ambiental que se ocasionaría -según estudios realizados en el nivel nacional (Universidad de la República- Uruguay) -en dicho río y su entorno.

Los reiterados cortes de ruta en el puente Fray Bentos -Puerto Unzué y en el de Paysandú- Colón, por parte de "piqueteros" ambientalistas argentinos han generado malestar y preocupación en el gobierno uruguayo, dado que han afectado la libre circulación de personas, la actividad comercial y el turismo de ese país. A su vez, las acusaciones hacia el gobierno uruguayo por parte del canciller argentino sobre las "violaciones del Tratado del Río Uruguay", profundizaron las tensiones entre ambos países. La crispación diplomática y las medidas directas por parte de grupos ambientalistas y vecinos del lugar, hicieron derivar el conflicto hasta la Corte Internacional de La Haya con el conocido dictamen a favor de Uruguay.

No obstante, más allá de la conquista uruguaya y de la derrota argentina -teñidos de contenidos nacionalistas y 
rivalidades históricas-, el tratamiento del propio conflicto como su causa revelan importantes aspectos relacionados con el desarrollo y el ambiente.

En primer lugar, cabe mencionar que el conflicto expresa las limitaciones del proceso de integración mercosuriano, en tanto no existe un marco regulatorio en temas ambientales que comprenda toda el área y permita resolver este tipo de conflictos entre sus miembros. Pero lo que se considera más grave, es la ausencia de una estrategia de desarrollo donde se incorpore adecuadamente la dimensión ambiental (temas como el desarrollo forestal, la preservación del agua, las especies animales y plantas, etc.). Esta ausencia parece ser consecuencia de las características del esquema de integración MERCOSUR centrado en el valor del mercado, el cual surge como acuerdos comerciales entre sus socios mayores (Argentina y Brasil) y como respuesta al contexto de globalización y competitividad comercial que se profundiza en la década de los 90. Desde entonces, si bien se han producido ciertos avances en materia comercial -al negociar como "bloque" frente a la Unión Europea por ejemplo-, las ventajas no se reparten en forma equitativa, resultando perjudicados los socios menores (Uruguay y Paraguay). No existió en sus inicios ni a lo largo del proceso de su conformación - $\mathrm{o}$ al menos sólo en forma precaria y débil- la necesaria participación ciudadana en la formulación de estrategias de desarrollo para la región sudamericana. En este sentido, cabe señalar que en este conflicto entre Argentina y Uruguay, más allá de los intereses reales poco claros y de su impacto en la economía uruguaya, las manifestaciones de "piqueteros" provocaron en el resto de la ciudadanía tanto en la Argentina como en el propio Uruguay, que el tema ambiental adquiriera notoriedad pública y dejará traslucir la falta de información del conjunto de la sociedad uruguaya sobre los impactos de tales plantas de celulosa. Ello no va en desmedro de la labor de las ONGs ambientalistas en Uruguay, pero su papel parecería fragmentar el tratamiento del tema ambiental en el conjunto de la sociedad y en la región.

En segundo lugar, importa analizar el hecho de la instalación -ahora legitimada internacionalmente, con intervención de instancias jurídicas en La Haya e informes técnicos del Banco Mundial-por parte de empresas transnacionales europeas, de las plantas de celulosa en Uruguay y su impacto ambiental en el contexto socioeconómico que rodea todo este proceso. Es decir, el interés por parte del gobierno uruguayo de esta "inversión" de capitales europeos, revela que el modelo de desarrollo actual no parece demasiado diferente a los anteriores -a pesar de los cambios político-ideológicos que ha vivido el paíspues no existe una integración adecuada de la dimensión ambiental. No obstante, cabe mencionar que tal acogida de "capital europeo" se produce en medio de la peor crisis socioeconómica del país en toda su historia, heredada de los gobiernos anteriores: alto índice de desempleo, la más importante migración de su población joven desde la época de la dictadura; casi el $40 \%$ de su población total por debajo de la línea de pobreza; escandalosos índices de pobreza infantil (en Montevideo llegó casi al $60 \%$, según datos estadísticos de la Intendencia) y aparición de mortalidad 
infantil por desnutrición en algunas regiones del país (departamento de Artigas); exclusión y desigualdad social crecientes; por mencionar algunos indicadores. Sin duda, este contexto aparece como un fuerte condicionante, pero ello no debería atenuar la importancia del tema ambiental en las estrategias y políticas de desarrollo.

Ahora bien, el problema de las industrias contaminantes no es nuevo ni exclusivo de Uruguay. Por su parte, Argentina posee en su territorio varias instalaciones industriales contaminantes al igual que el resto de los países del MERCOSUR. En este sentido, si bien es cierto que el esquema actual de integración del MERCOSUR no le ofrece a los países pequeños el espacio y las oportunidades necesarias para su desarrollo más que una competencia feroz y una cadena de litigios, el tema ambiental debería formar parte de estrategias de desarrollo en común más allá de las zonas fronterizas, que le permitiera a cada país superar sus niveles de pobreza y desigualdad social consecuencia de la aplicación del modelo de desarrollo neoliberal durante las posdictaduras.

En tercer lugar, importa mencionar algunos de los impactos que -según los estudios realizados por la Facultad de Ciencias (Universidad de la República) en el presente año incorporando resultados de investigaciones de nivel mundial- generan las plantas de celulosa y del modelo forestal asociado a ellas. Desde estos estudios, se plantea que un cambio en el uso del suelo modifica la capacidad de los ecosistemas para producir bienes y servicios. $\mathrm{La}$ pasta de celulosa que se extrae de los árboles requiere de unas 300.000 hectáreas forestadas al año. Sin embargo, el área potencialmente forestable en Uruguay apenas llega a un $44 \%$ de esa cantidad, dado que la deforestación disminuye el rendimiento hidrológico del suelo, afecta ríos y arroyos. Pero además, se señala que generaría efectos negativos sobre la biota y ecosistemas acuáticos, retardando así la maduración sexual de los peces. Por su parte, varias organizaciones ambientalistas nacionales e internacionales han denunciado a las empresas involucradas por el efecto contaminante de esta actividad industrial.

Finalmente, en este caso, el ambiente ha convocado la atención del sistema político, de las autoridades jurídicas nacionales e internacionales, de científicos, de movimientos ambientalistas nacionales e internacionales y de la opinión pública, a partir de intereses económicos por parte de las empresas europeas ENCE y Botnia en el contexto de la expansión de empresas transnacionales, propio de la globalización. Todo el proceso y la forma de su resolución reflejan que el tema ambiental no ha sido lo suficientemente integrado en la agenda nacional (ni regional mercosuriana) de desarrollo, e incluso puede llegar a ser concebido como un obstáculo para la actividad económico-industrial. Por otra parte, no es la primera vez ni será la última en que empresas europeas o estadounidenses busquen trasladar industrias contaminantes de sus países hacia América Latina, donde las restricciones ambientales en ausencia de marcos regulatorios en la materia o con estándares inferiores de contaminación, no les impidan alcanzar sus objetivos económicos. 


\section{A modo de conclusión: aportes teóricos para un modelo alternativo de desarrollo}

En esta última parte y como un aporte a la construcción de un modelo alternativo de desarrollo para la región, se expondrán algunas corrientes de pensamiento que cuestionan el paradigma de desarrollo economicista, sustento del proyecto civilizatorio de la modernidad europea y que han estado subyacentes durante todo el análisis realizado.

A lo largo del trabajo, ha quedado reflejado que nuestra región no escapa a la "crisis ambiental" expandida en todo el mundo y cuyo origen se encuentra en el llamado Primer Mundo o mundo "industrializado". Dicha crisis no es sólo ambiental, sino una crisis del pensamiento occidental, cuya racionalidad científica e instrumental produjo este mundo como "un orden cosificado y fragmentado", a partir del dominio y control de la naturaleza. Es decir, la racionalidad teórica e instrumental construye y destruye el mundo. Por tanto, es necesario hoy más que nunca repensar el ser del mundo complejo, entender sus formas de complejización, para desde allí abrir nuevas vías del saber hacia la reconstrucción y reapropiación del mundo ${ }^{11}$. Desde la complejidad ambiental que nos propone E. Leff, es posible deconstruir y reconstruir el pensamiento, descubrir los errores de la historia en las certidumbres sobre el mundo con falsos fundamentos, conocer el ser de la complejidad que fue olvidado con la división entre ser y ente (Platón), sujeto $\mathrm{y}$ objeto (Descartes), para aprehender

11 Leff, Enrique et al. (2000). La complejidad ambiental. México: siglo XXI. el mundo cosificándolo, objetivándolo, homogeneizándolo. La idea monoteísta cristiana fue trasladada al campo del conocimiento como un logos rector del mundo, abriendo de esta manera un proyecto unificador desde la idea de una razón ordenadora y dominadora. Desde allí se expande una ciencia económica basada en un ideal mecanicista, en las leyes ciegas del mercado, que han determinado la economización del mundo y el predominio de la razón instrumental sobre la naturaleza y la cultura. La complejidad ambiental permite una nueva reflexión sobre la naturaleza del ser, del saber y del conocer, sobre la hibridación de conocimientos en la interdisciplinariedad y la transdisciplinariedad, el diálogo entre saberes y la inserción de la subjetividad y de los valores en las estrategias vinculadas con la naturaleza. Desde la complejidad ambiental, el mundo se libera del "logocentrismo" y abre las potencialidades de la naturaleza y la construcción de utopías desde la fecundidad de la otredad. En este sentido, la complejidad manifiesta la imposibilidad de la unidad, pues el signo es la diferencia, lo cual supone una reconstitución de las identidades, que se aparten de lo idéntico para forjar lo inédito. Se promueven, así, las identidades híbridas e identificaciones solidarias en la diferencia. Y se propone, al fin, una "racionalidad ambiental" que integre los potenciales de la naturaleza, los valores humanos y las identidades culturales en prácticas productivas sustentables capaces de construir un nuevo orden social.

En la búsqueda por romper con la racionalidad instrumental que coloca al ser humano por encima de la naturaleza, han surgido enfoques alternativos que buscan 
una relación dialógica y armoniosa con la naturaleza (ecoteologías como L. Boff y diversas cosmovisiones indígenas). Aparecen corrientes de pensamiento que se inspiran en las concepciones indígenas y campesinas basadas en la pertenencia y empatía con el ambiente donde el ser humano vuelve a ser parte de la naturaleza, rompiendo así con la dualidad occidental. En este sentido, cabe destacar que existe una tradición indígena que supera tanto el antropocentrismo como el biocentrismo. Se trata de los guaraníes presentes actualmente en el sur de Bolivia, Brasil, Paraguay y el norte de Argentina. Ellos parten de un concepto del "sí-mismo" (persona) y del ambiente donde uno contiene al otro. No existe separación pues no se la reconoce. La autodefinición de la persona requiere un ambiente.

Lo expuesto hasta el momento no desecha las posibilidades de alternativa que ofrece el concepto de "desarrollo sostenible", pero todo depende de su contenido. Una forma de entenderlo extiende el concepto de "capital" a la naturaleza y promueve el concepto de "capital natural". Para esta corriente, la sostenibilidad implica mantener constante el capital total, sumándose el capital natural con las acciones humanas. A esta perspectiva se la denomina como "sostenibilidad débil", al acepar la sustitución de diferentes formas del capital. Una segunda corriente - de "sostenibilidad fuerte"-, no acepta tal sustitución entre formas de capital, propone mantener el capital natural, el cual se convierte en un objetivo en sí mismo del desarrollo sostenible. Se reconoce que existe un stock de ese tipo de capital que debe ser protegido. Una tercera tendencia -de "sostenibilidad superfuerte"- se cuestiona el uso del concepto "capital" sobre la naturaleza. En ella, el ambiente es valorado desde múltiples perspectivas, que deben tener un campo político de argumentación y se apuesta a la preservación de la naturaleza al reconocerle valores propios. (Gudynas, 2002) Queda claro que las predominantes en la actualidad son las primeras dos concepciones de "sostenibilidad".

En síntesis, estos aportes teóricos y corrientes de pensamiento permiten concebir un modelo de desarrollo alternativo al actual, donde la relación con la naturaleza no esté signada por el valor económico y se atienda a las necesidades básicas de los seres humanos sin perjudicar los derechos de la naturaleza. Un modelo donde se conciba el ambiente como totalidad que supone la diversidad, pues valora y respeta las diferencias identitarias.

\section{Bibliografía}

Comisión de Desarrollo y Medio Ambiente de América Latina y el Caribe (1989). Nuestra propia agenda. Nueva York, Washington, Santiago de Chile: PNUD-BID.

Boff L. et al. (1998). Filosofía del Ambiente. Heredia: EUNA.

Gudynas, E. (2002). Ecología, economía y ética del desarrollo sostenible en América Latina, San José: EUNED Leff, E. et al. (2000). La complejidad ambiental. México: Siglo XXI.

López, M. (2004). El problema ambiental: Ahora resulta que la enfermedad cura. En: Reflexiones en torno al Tratado de Libre Comercio. Razones para su rechazo. Carlos Aguilar Sánchez (ed.). San José: Colección Universitaria. 
Mora, A. (2005). La filosofía latinoamericana. Introducción histórica. San José: EUNED.

Mora Jiménez, H. (2004). 101 razones para oponerse al Tratado de Libre
Comercio entre Centroamérica y Estados Unidos. Heredia: ESEUNA. Sejenovich, $H$. (s.f.). La viabilidad del desarrollo sustentable en América Latina y el Caribe. 